\title{
Evaluation of Transcription Factor 7 like 2 polymorphisms and haplotypes in risk of Type 2 Diabetes
}

\author{
Ramin Saravani*, Zahra Irani, Hamid Reza Galavi \\ Cellular and Molecular Research Center and Department of Clinical Biochemistry, School of \\ Medicine, Zahedan University of Medical Sciences, Zahedan, Iran
}

\begin{abstract}
Type 2 diabetes (T2D) is a chronic disorder with different genetics and environmental factors. It is one of growing diseases in the world. Previous studies show association between Transcription Factor 7 Like2 (TCF7L2) and T2D. The current study set to evaluate the relation between TCF7L2 polymorphisms and T2D in Southeast Iran. The present case-control study was done on 250 T2D and 250 healthy controls (HCs). For genotyping polymorphisms TCF7L2 (rs11196205) and (rs4132670) Amplification-Refractory Mutation System-Polymers Chain Reaction (ARMS-PCR) was used. The results showed frequency rates of GC and CC genotypes increased in patients compared to controls (31\% vs. $6 \%$ and $55 \%$ vs. $8 \%$, respectively), showing a statistically significant difference $(O R=2.67(1.37-5.21), P<0.05$ and $O R=3.31(1.92-5.71), P<0.05$, respectively). The $C$ allele was associated with an increased risk of $T 2 D$, with the frequency of $28 \%$ and $11 \%$ in patients and controls, respectively $(O R=3.11$ (2.22-4.37), P<0.05). Another Polymorphism of this gene TCF7L2 (rs4132670) was not associated with T2D. Furthermore, the haplotype analysis revealed that $r s 11196205 \mathrm{C} / \mathrm{rs} 4132670 \mathrm{C}$ and $\mathrm{rs} 11196205 \mathrm{C} / \mathrm{rs} 4132670 \mathrm{~T}$ are risk factors against $T 2 D(O R=2.08$ (1.49-2.86, $P<0.05$ and $O R=1.72$ (1.06-2.78) $P<0.05$, respectively). The findings demonstrated that TCF7L2 (rs11196205) genotypes $G C, C C$, and allele (C) confer risk for susceptibility to T2D.

Keywords: Gene polymorphism; Haplotype; Hyperglycemia; TCF7L2.
\end{abstract}

Received: 05 ${ }^{\text {th }}$ June 2016; Accepted: 09th October 2016; Published: $11^{\text {th }}$ October 2016.

\section{Introduction}

Type 2 diabetes (T2D) is a heterogeneous and multi-factorial metabolic disease (genetic and environmental factors), characterized by increase in peripheral blood glucose (hyperglycemia) due to insulin resistance (decreased action of insulin at targeted tissues) and/or pancreatic beta-cell dysfunction (1). T2D is known as non-insulin dependent diabetes, accounting for $90 \%$ of diabetic patients who possess several pathogenic factors such as lifestyle, overeating, and genetic elements, implying a 2.4 fold increased risk for T2D in individuals with positive family history (2). To manage their hyperglycemia and protect themselves against long-term complications of the disease such as retinopathy, nephropathy, neuropathy, and cardiovascular problems (3), patients with T2D must use drugs such as 1.oral hypoglycemic agents, oral sulfonylureas 1 st generation (like Chlorpropamide, Tolazamide, and Tolbutamide), oral sulfonylureas 2 nd generation

* Corresponding author: Ramin Saravani, Cellular and Molecular Research Center and Department of Clinical Biochemistry, School of Medicine, Zahedan University of Medical Sciences, Zahedan, Iran e-mail: saravaniramin@, yahoo.com 
(like Glimepiride, Glipizide, Glyburide, and Gliclazide), non-sulfonylurea secretagogues (like Nateglinide and Repaglinide), biguanides (like Metformin), Thiazolidinediones (like Pioglitazone and Rosiglitazone), and alpha-glucosidase inhibitors (like Acarbose) 2. Novel targets for increased insulin action include glucagon-like peptide-1 (GLP-1), dipeptidyl peptidase IV (DDP-4) inhibitors, glucagon receptor antagonists, and sodium-glucose co-transporter 2 (SGLT2) inhibitors $(2,4)$.

The prevalence of diabetes in Eastern Mediterranean and West Asian regions including Iran was $9.3 \%$ in 2010 and will reach $10.8 \%$ in 2030 , and as regards the worldwide prevalence, diabetes among adults is predicted to rise to approximately 439 million patients in 2030, and in developing countries such as Iran, this prevalence will be much greater than in developed countries (5).

Genes have important roles in pathogenesis of T2D. Transcription Factor 7 Like 2 (TCF7L2) (also known as Transcription Factor 4) is located on chromosome 10q25.3 and consists of 17 exons (6); this gene is expressed in various tissues, especially tissues involved in the pathogenesis of T2D including fat, liver, and pancreatic islets of Langerhans. It acts as transcription factor (TF) in the Wnt-signaling pathway. This signaling pathway has an important role in embryogenesis consisting of adipocyte and pancreatic tissue formation (7). Previous studies show that TCF7L2 has a key role in insulin secretion and synthesis, which is also a key regulator of pro-insulin processing and production (8).

Some variants of TCF7L2 gene reduce insulin secretion and increase the risk of T2D (6). Several studies indicate TCF7L2 polymorphisms' association with T2D (9). Accordingly, the current inquiry set to evaluate two Single Nucleotide Polymorphisms (SNPs) (rs11196205 and rs4132670) in TCF7L2 gene in a case-control study on Southeast Iran.

\section{Materials and methods}

A case-control study was performed on 250 participants with T2D in Ali-Asghar Hospital of Zahedan, Southeast Iran (Sep, 2015). All the individuals were confirmed as T2D patients through biomedical tests such as Fast Blood Sugar (FBS) (Enzymatic Colorimetric Assay, Pars-Azmoon Co, Tehran, Iran) on Autoanalyzer BT 1500 (Biotecnica, Italy) more or equal to $126 \mathrm{mg} / \mathrm{dl}$, Hemoglobin A1c (HbA1c) (NycoCardTM HbA1c on NycoCard Reader II (Axis-Shield, Oslo, Norway)) more or equal to $6.7 \%$. Although more or equal to $6.5 \%$ of $\mathrm{HbA} 1 \mathrm{c}$ is international guideline for diagnose of T2D, normal range in our region (Southeast of Iran) taking into account gender, age, and ethnicity is $6.7 \%$ and were considered by endocrinologists in diagnosing all T2D patients.

In total, 250 healthy controls (HCs) were enrolled on a voluntary basis without any systemic disease and relation with T2D from Razmjo-Moghadam, Zahedan, Southeast Iran, and they had normal biomedical data (inclusion criteria for $\mathrm{HCs}$ were normal $\mathrm{FBS}$ and/or $\mathrm{HgAlC}$, $\mathrm{FBS} \leq 100$ or $\mathrm{HbA} 1 \mathrm{c}<6.7$ ). The convenient sampling method was used for both groups. All T2D and HCs participants were Iranian and provided their informed consents before taking part in the study. The ethics committee of Zahedan University of Medical Sciences approved the protocol of the study.

\section{Genotype analysis}

The salting out phenol chloroform method was used for extraction of genomic DNA from $2 \mathrm{ml}$ peripheral blood leukocyte (stored at $-20^{\circ} \mathrm{C}$ until genotyping). The primers were designed based on ARMS method (Table 1). The final PCR mixture volume was $20 \mu$ consisting of $\sim 80-100 \mathrm{ng}$ genomic DNA, $10 \mathrm{pM}$ of each primer (forward and reverse), $10 \mu \mathrm{l}$ master mix, and $7 \mu \mathrm{l}$ distilled water. Bio-Rad thermal cycler (Bio-Rad, Hercules, CA, USA) was used 
Table 1. Allele-Specific Polymerase (ASP), Polymerase Chain Reaction Primers sequences

\begin{tabular}{lcc}
\hline Primer 5'-3' & Product & Method \\
\hline Rs11196205 & $211 \mathrm{bp}$ & ARMS \\
\hline Fw;CCATAACTCTCTTACATACTGCCG & & \\
\hline Fm:CCATAACTCTCTTACATACTGCCC & & \\
\hline R:TGCTACTGTGCATGATCCTG & & \\
\hline Rs4132670 & $256 \mathrm{bp}$ & \\
\hline Rw:GTGCAGCCCAGACATAGCAGAG & & \\
\hline Rm:GTGCAGCCCAGACATAGCAGAA & & \\
\hline F:AGAGTTGCATCGTATGCCAA & & \\
\hline
\end{tabular}

for amplification with the following condition: rs 11196205 , an initial denaturation at $95^{\circ} \mathrm{C}$ for 6 min followed by 30 cycles at $95^{\circ} \mathrm{C}$ for $30 \mathrm{sec}$, annealing $55^{\circ} \mathrm{C}$ for $30 \mathrm{sec}$, extension at $72^{\circ} \mathrm{C}$ for $30 \mathrm{sec}$, and after the completion of the thirtieth cycle, the final extension was at $72^{\circ} \mathrm{C}$ for $6 \mathrm{~min}$. The rs4132670 condition was similar to previous SNP (rs11196205), except that the annealing temperature was $58^{\circ} \mathrm{C}$.

PCR products were verified on Agarose 2\% containing ethidium bromide $(0.6 \mu \mathrm{g} / \mathrm{ml})$, observed with gel electrophoresis (under UV light). The sizes of PCR products were 211 base pair (bp) for rs11196205 and 256bp for rs4132670. Some samples, either T2D or HCs, were re-genotyped randomly; the present results confirmed the past findings.

\section{Statistical analysis}

SPSS 16.0 (SPSS Ine., Chicago, USA) was used for data analysis. Logistic regression was used to find the association between SNPs and T2D and compute $95 \%$ confidence interval $(95 \% \mathrm{CI})$ and the Odd Ratio (OR). Independent samples t-test and $\chi^{2}$ test were used for analyzing clinical and demographic data. The significance levels for all tests were considered $P \leq 0.05$. The frequency of haplotypes was calculated using PHASE version-2.1 software $(19,20)$. Haplotypes with estimated frequency $<5 \%$ were excluded from the analysis. Multivariate logistic regression models were used to evaluate the associations between T2D and TCF7L2 genotypes.

\section{Results}

\section{Subjects'characteristics}

The clinical and demographic features of the T2D patients and HCs are shown in Table 2. No significant difference was found regarding age, gender, triglyceride (TG), and low-density lipoprotein (LDL) between two groups $(\mathrm{P}>0.05)$. There were statistically significant differences in total cholesterol (TC) $(\mathrm{P}=0.02)$, and high-density lipoprotein (HDL) $(\mathrm{P}=0.002)$ between the groups; furthermore, the level of FBS, HbAlc, and Body Mass Index (BMI) were significantly higher in the T2D group $(\mathrm{P}<0.0001)$.

\section{Genotyping of TCF7L2 SNPs}

The two SNPs of TCF7L2 gene were successfully genotyped in $250 \mathrm{~T} 2 \mathrm{Ds}$ and $250 \mathrm{HCs}$. The frequency rates of alleles and genotypes of TCF7L2 polymorphisms are shown in Table 3. All the loci did not conform to the Hardy-Weinberg equilibrium (HWE) in T2D and HCs $(\mathrm{P}<0.05)$. In T2D group, the genotype distribution of both SNPs, rs11196205G/C and rs4132670C/T, was not in $\operatorname{HWE}\left(\mathrm{X}^{2}=120.34, \mathrm{P}<0.05\right.$ and $\mathrm{X}^{2}=122.14$, $\mathrm{P}<0.05$, respectively), and in HCs, the genotype distribution of $\mathrm{rs} 11196205 \mathrm{G} / \mathrm{C} \quad\left(\mathrm{X}^{2}=129.05\right.$, 
Table 2. Demographic characteristics of T2D patients and controls

\begin{tabular}{lccc}
\hline & T2D $(\mathbf{n} \pm$ SD) & Controls $(\mathbf{n} \pm$ SD) & P-value \\
\hline Age $($ year) & $54.87 \pm 10.13$ & $48.86 \pm 10.01$ & 0.593 \\
\hline Sex $($ Female/male) & $183 / 67$ & $174 / 76$ & 0.429 \\
\hline FBS $(\mathrm{mg} / \mathrm{dl})$ & $188.40 \pm 86.45$ & $97.70 \pm 19.21$ & $<0.0001$ \\
\hline TC $(\mathrm{mg} / \mathrm{dl})$ & $183 \pm 44.31$ & $181.84 \pm 36.1$ & 0.020 \\
\hline TG $(\mathrm{mg} / \mathrm{dl})$ & $161.40 \pm 83.24$ & $148.1 \pm 94.59$ & 0.792 \\
\hline HDL $(\mathrm{mg} / \mathrm{dl})$ & $55.4 \pm 20.17$ & $54.01 \pm 14.68$ & 0.002 \\
\hline LDL $(\mathrm{mg} / \mathrm{dl})$ & $97.21 \pm 34.33$ & $104.49 \pm 29.06$ & 0.355 \\
\hline BMI $(\mathrm{kg} / \mathrm{m} 2)$ & $27.63 \pm 5.49$ & $21.48 \pm 2.43$ & $<0.0001$ \\
\hline HbA1c & $9.21 \pm 1.78$ & $4.93 \pm 0.94$ & $<0.0001$ \\
\hline
\end{tabular}

$F B S=$ Fast blood sugar; $T C=$ Total Cholesterol; $T G=$ Triglyceride; $H D L=$ High-dense lipoprotein; $L D L=$ Low-dense lipoprotein; BMI = Body Mass Index; HbAlc = Hemoglobin Alc.

$\mathrm{P}<0.05)$ and $\mathrm{rs} 4132670 \mathrm{C} / \mathrm{T}\left(\mathrm{X}^{2}=145.88, \mathrm{P}<0.05\right)$ was not in HWE. In rs11196205G/C of TCF7L2 gene, the frequencies of $\mathrm{GG}, \mathrm{GC}$, and $\mathrm{CC}$ genotypes were $66 \%, 12 \%$, and $22 \%$ in $\mathrm{T} 2 \mathrm{D}$, and $86 \%, 6 \%$, and $8 \%$ in $\mathrm{HCs}$, respectively. GC genotype of this SNP (rs11196205G/C) was signifi- cantly different between T2Ds and $\mathrm{HCs}$ (GC vs. $\mathrm{GG}, \mathrm{OR}=2.67,95 \% \mathrm{CI}=1.27-5.21, \mathrm{P}=0.004)$ as risk factor, and $\mathrm{CC}$ genotype was also strongly associated with T2D as risk factor (CC vs. GG, $\mathrm{OR}=3.31,95 \% \mathrm{CI}=1.92-5.71, \mathrm{P}<0.0001)$. The frequencies of alleles of rs $11196205 \mathrm{G} / \mathrm{C}$ were

Table 3. Genotype and allele frequency of TCF7L2 (rs 11196205 and rs4132670) polymorphisms in T2D and controls

\begin{tabular}{|c|c|c|c|c|}
\hline & $\begin{array}{c}\text { T2D } \\
\text { n(\%) }\end{array}$ & $\begin{array}{c}\text { Controls } \\
\mathbf{n}(\%)\end{array}$ & P-value & OR $(95 \%$ CI) \\
\hline \multicolumn{5}{|c|}{ TCF7L2(rs11196205) } \\
\hline GG, n (\%) & $164(66 \%)$ & $215(86 \%)$ & & Ref $=1.00$ \\
\hline $\mathrm{GC}, \mathrm{n}(\%)$ & $31(12 \%)$ & $14(6 \%)$ & 0.004 & $2.67(1.37-5.21)$ \\
\hline $\mathrm{CC}, \mathrm{n}(\%)$ & $55(22 \%)$ & $21(8 \%)$ & $<0.0001$ & $3.31(1.92-5.71)$ \\
\hline \multicolumn{5}{|l|}{ Allele } \\
\hline $\mathrm{G}, \mathrm{n}(\%)$ & $359(72 \%)$ & $444(89 \%)$ & & 1.00 \\
\hline $\mathrm{C}, \mathrm{n}(\%)$ & $141(28 \%)$ & $56(11 \%)$ & $<0.0001$ & $3.11(2.22-4.37)$ \\
\hline \multicolumn{5}{|c|}{ TCF7L2(rs4132670) } \\
\hline $\mathrm{CC}, \mathrm{n}(\%)$ & $133(53 \%)$ & $127(51 \%)$ & & 1.00 \\
\hline CT, n (\%) & $36(14 \%)$ & $29(12 \%)$ & 0.427 & $1.25(0.72-2.15)$ \\
\hline TT, n (\%) & $81(33 \%)$ & $94(38 \%)$ & 0.447 & $0.86(0.59-1.26)$ \\
\hline \multicolumn{5}{|l|}{ Allele } \\
\hline $\mathrm{C}, \mathrm{n}(\%)$ & $302(60 \%)$ & $283(57 \%)$ & & 1.00 \\
\hline $\mathrm{T}, \mathrm{n}(\%)$ & $198(40 \%)$ & $217(43 \%)$ & 0.247 & $0.85(0.66-1.10)$ \\
\hline
\end{tabular}

$C I=$ confidence interval; $O R=$ odds ratio. 
Table 4. Single nucleotide Polymorphism association with T2D and Control

\begin{tabular}{|c|c|c|c|c|}
\hline & T2D & CONTROL & P-Value & OR(95\%CI) \\
\hline \multicolumn{5}{|c|}{ TCF7L2(rs11196205) } \\
\hline \multicolumn{5}{|l|}{ Dominant } \\
\hline GG & $164(66 \%)$ & $215(56 \%)$ & & $\mathrm{REF}=1$ \\
\hline $\mathrm{GC}+\mathrm{CC}$ & $86(34 \%)$ & $35(14 \%)$ & $<0.0001$ & $3.23(2.08-5)$ \\
\hline \multicolumn{5}{|l|}{ Recessive } \\
\hline $\mathrm{GG}+\mathrm{GC}$ & $195(78 \%)$ & $229(91.6 \%)$ & & 1 \\
\hline $\mathrm{CC}$ & $55(22 \%)$ & $21(8.4 \%)$ & $<0.0001$ & $3.03(1.85-5.26)$ \\
\hline \multicolumn{5}{|c|}{ TCF7L2(rs4132670) } \\
\hline \multicolumn{5}{|c|}{ Dominant } \\
\hline $\mathrm{CC}$ & $133(53 \%)$ & $127(51 \%)$ & & 1 \\
\hline CT-TT & $117(47 \%)$ & $123(49 \%)$ & 0.59 & $0.91(0.64-1.28)$ \\
\hline \multicolumn{5}{|l|}{ Recessive } \\
\hline $\mathrm{CC}+\mathrm{CT}$ & $169(68 \%)$ & $156(62 \%)$ & & 1 \\
\hline TT & $81(32 \%)$ & $94(38 \%)$ & 0.22 & $0.81(0.55-1.15)$ \\
\hline
\end{tabular}

$72 \%$ for $\mathrm{G}$ allele and $28 \%$ for $\mathrm{C}$ allele in $\mathrm{T} 2 \mathrm{D}$. On the other hand, the frequencies of $\mathrm{G}$ and $\mathrm{C}$ alleles were $89 \%$ and $11 \%$ in $\mathrm{HCs}$, respectively. The $\mathrm{C}$ allele in rs $11196205 \mathrm{G} / \mathrm{C}$ was strongly associated with T2D (C vs. G, OR=3.11, 95\% CI=2.22-4.37, $\mathrm{P}<0.0001)$ as risk factor.

In rs4132670C/T of TCF7L2 gene, the frequency rates of CC, CT, and TT genotypes in T2Ds were $53 \%, 14 \%$, and $33 \%$, and $51 \%, 12 \%$, and $38 \%$ in HCs, respectively. Both genotypes, CT and TT of this SNP (rs4132670C/T), were not significantly different between T2Ds and HCs ( $\mathrm{P}>0.05)$. There was no association between $\mathrm{T}$ allele of rs4132670C/T and T2D ( $>0.05)$, while the frequencies of $\mathrm{C}$ and $\mathrm{T}$ alleles were $60 \%$ and $40 \%$ in T2Ds, and $57 \%$ and $43 \%$ in HCs, respectively.
The dominant and recessive statuses were studied (Table 4) for either rs11196205 or rs4132670. The results showed that in rs$11196205 \mathrm{G} / \mathrm{C}, \mathrm{GC}+\mathrm{CC}$ was associated with T2D in dominant status $(\mathrm{GC}+\mathrm{CC}$ vs. GG, $\mathrm{OR}=3.23,95 \% \mathrm{CI}=2.08-5, \mathrm{P}<0.0001)$, and $\mathrm{CC}$ was associated with $\mathrm{T} 2 \mathrm{D}$ in recessive status (CC vs. $\mathrm{GG}+\mathrm{GC}, \mathrm{OR}=3.03,95 \% \mathrm{CI}=1.85-5.26$, $\mathrm{P}<0.0001)$. There was no significant association regarding $\mathrm{T} 2 \mathrm{D}$ in both statuses (dominant and recessive) in rs4132670.

The frequency rates of four common haplotypes of two SNPs in TCF7L2 gene (rs11196205 and rs4132670) are shown in Table 5. Although there was no significant difference between GT haplotype and T2D ( $\mathrm{P}=0.93), \mathrm{CC}$ and CT haplo-

Table 5. Haplotype association with T2D

\begin{tabular}{llllll}
\hline Rs11196205 & Rs4132670 & T2D & Control & P-value & OR(95\%CI) \\
\hline G & C & 0.3956 & 0.4928 & - & Ref=1 \\
\hline G & T & 0.3224 & 0.3952 & 0.93 & $0.99(0.8-1.23)$ \\
\hline C & C & 0.2084 & 0.0732 & $<0.0001$ & $2.08(1.49-2.86)$ \\
\hline C & T & 0.0736 & 0.0388 & 0.026 & $1.72(1.06-2.78)$ \\
\hline
\end{tabular}


types were significantly different between T2D and $\mathrm{HCs}$, hence the risk of T2D increased to 2.08 fold in the presence of CC haplotype ( $\mathrm{OR}=2.08$, $95 \% \mathrm{CI}=1.49-2.86)$ and increased to 1.72 fold in the presence of CT haplotype $(\mathrm{OR}=1.72,95 \%$ $\mathrm{CI}=1.06-2.78, \mathrm{P}=0.026$ ). Finally, multivariate logistic regression was used to adjust for potential confounding factors including gender, age, FBS, TC, TG, HDL, and LDL for both SNPs (Table 6), indicating that $\mathrm{CC}$ vs. GG genotypes of rs1196205 was associated with T2D $(\mathrm{OR}=3.98,95 \% \mathrm{CI}=1.81-8.77, \mathrm{P}=0.001)$, while GC vs. GG was not associated with the risk/protection of T2D $(\mathrm{P}>0.05)$ in this SNP. Considering rs4132670 genotype, there was no statistically significant difference among the groups.

\section{Discussion}

Type 2 diabetes, as epidemic disease, is strongly associated with TCF7L2 and also complications and risk factors such as cardiovascular diseases and obesity $(6,10)$. This gene is a member of TCF/lymphoid enhancer-bind- ing factor of transcription factors involved in Wnt-signaling (11).

In the current study, two SNPs of TCF7L2 in T2D were evaluated. The results showed that GC and CC genotypes of rs11196205 of TCF7L2 gene were strongly associated with T2D as risk factor, and $\mathrm{C}$ allele of this gene SNP (rs4132670) was not associated with T2D. However, previous studies have proved that rs7903146C/T polymorphism of TCF7L2 is associated with T2D in different ethnic populations (12-15). There is little data regarding the role of TCF7L2 polymorphism (rs11196205 and rs4132670), especially rs4132670 polymorphism. Luo et al. found that, in meta-analysis of the association between T2D and SNPs of TCF7L2 in East-Asian population, rs11196205 was significantly associated with T2D (16). In another investigation in Hong-Kong, MCY Ng et al. showed that rs11196205 was associated with T2D as risk factor (17). Tangjittipokin et al., similarly, found that GC in Thai patients was associated with $\mathrm{T} 2 \mathrm{D}$, with $\mathrm{OR}$ equal to

Table 6. Multivariate logistic regression analysis of the relationship between $T C F 7 L 2$ polymorphisms in T2D*

\begin{tabular}{lccccc}
\hline $\begin{array}{l}\text { Genotype } \\
\text { rs11196205 }\end{array}$ & P-Value & $\begin{array}{c}\text { Odds ratio (95\% } \\
\text { CI) }\end{array}$ & $\begin{array}{c}\text { Genotype } \\
\text { rs4132670 }\end{array}$ & P-Value & Odds ratio (95\% CI) \\
\hline GG & & ref & CC & & ref \\
\hline GC & 0.132 & $2.28(0.78-6.67)$ & CT & 0.402 & $1.456(0.605-3.509)$ \\
\hline CC & 0.001 & $3.98(1.81-8.77)$ & TT & 0.796 & $0.919(0.484-1.745)$ \\
\hline Sex & 0.901 & $0.958(0.489-1.876)$ & Sex & 0.840 & $1.070(0.560-2.041)$ \\
\hline Age & 0.001 & $1.06(1.02-1.09)$ & Age & 0.001 & $1.050(1.020-1.081)$ \\
\hline FBS & $<0.0001$ & $1.05(1.04-1.07)$ & FBS & $<0.0001$ & $1.052(1.040-1.066)$ \\
\hline TC & 0.824 & $1.002(0.988-1.015)$ & TC & 0.760 & $1.002(0.989-1.015)$ \\
\hline TG & 0.785 & $1.001(0.997-1.004)$ & TG & 0.758 & $1.001(0.997-1.004)$ \\
\hline HDL & 0.254 & $1.013(0.991-1.035)$ & HDL & 0.184 & $1.014(0.993-1.036)$ \\
\hline LDL & 0.181 & $0.990(0.974-1.047)$ & LDL & 0.196 & $0.990(0.976-1.005)$ \\
\hline
\end{tabular}

*Multivariate logistic regression was used to adjust for potential confounding factors including sex, age, FBS, TC, TG, HDL, and LDL. FBS: Fast blood sugar, TC: Total Cholesterol, TG: Triglyceride, HDL; High-density lipoprotein, LDL: Low-density lipoprotein. 


\subsection{3 (18). This SNP (rs11196205) of TCF7L2} was strongly associated with T2D in European-derived population, Pima Indians, and Chinese (19-22). In contrast, this SNP was investigated in South Sweden, revealing that neither GC genotype nor CC genotype was associated with T2D (9). There is little data on the association between rs4132670 and T2D. Pang et al. found that rs4132670 may play a role in gene expression of TCF7L2 associated with T2D (23). Another investigation was done by Karnes et al. on hydrochlorothiazide-induced diabetes, revealing that rs4132670 was associated with their study population (24). The present study had some limitations such as calorie intake, sedentary life style, and other environmental confounding factors and some other characteristics such as ethnicity, life style, and socioeconomic status of the population.

The deviation from HWE is not clear in the current study population; it may have several reasons such as small sample size, migration, or consanguineous marriages that are common in this area of the country (Zahedan, southeast Iran).

The results indicated that rs11196205 of TCF7L2 gene was associated with T2D, so C allele of this SNP is a risk factor for this disease; however, another SNP (rs4132670) of TCF7L2 gene was not associated with T2D in the study population. CC haplotype was strongly associated with T2D as risk factor, while CT haplotype was slightly associated with T2D.

\section{Acknowledgments}

This paper was funded and supported by Zahedan University of Medical Sciences.

\section{Conflict of Interests}

The authors declare that there is no conflict of interests to disclose.

\section{References}

1. Hara K, Shojima N, Hosoe J, Kadowaki T. Genetic architecture of type 2 diabetes. Biochem Biophys Res Commun. 2014;452(2):213-20. DOI: 10.1016/j. bbrc.2014.08.012.

2. Stumvoll M, Goldstein BJ, van Haeften TW. Type 2 diabetes: principles of pathogenesis and therapy. The Lancet. 2005;365(9467):1333-46. DOI: 10.1016/ S0140-6736(05)61032-X.

3. Saravani R, Esmaeeli E, Tamendani MK, Nejad MN. Oxytocin Receptor Gene Polymorphisms in Patients With Diabetes. Gene Cell Tissue. 2015;2(2): e27904. DOI: $10.17795 /$ gct-27904.

4. Tahrani AA, Piya MK, Kennedy A, Barnett AH. Glycaemic control in type 2 diabetes: targets and new therapies. Pharmacol Ther. 2010;125(2):328-61. DOI: 10.1016/j.pharmthera.2009.11.001.

5. Nolan CJ, Damm P, Prentki M. Type 2 diabetes across generations: from pathophysiology to prevention and management. The Lancet. 2011;378(9786):169-81. DOI: 10.1016/S0140-6736(11)60614-4.

6. Allahdini M, Kamalidehghan B, Akbari L, Azadfar P, Rahmani A, Ahmadipour F, et al. Prevalence of the rs7903146C $>$ T polymorphism in TCF7L2 gene for prediction of type 2 diabetes risk among Iranians of different ethnicities. Drug Des Devel Ther. 2015;9:5835.

7. Guja C, Gagniuc P, Ionescu-Tîrgovişte C, editors. Genetic factors involved in the pathogenesis of type 2 diabetes. Proc Rom Acad Series B; 2012.

8. Zhou Y, Park S-Y, Su J, Bailey K, Ottosson-Laakso E, Shcherbina L, et al. TCF7L2 is a master regulator of insulin production and processing. Hum Mol Gen. 2014:ddu359.

9. Mayans S, Lackovic K, Lindgren P, Ruikka K, Ågren $\AA$, Eliasson M, et al. TCF7L2 polymorphisms are associated with type 2 diabetes in northern Sweden. Eur J Hum Genet. 2007;15(3):342-6. DOI: 10.1038/ sj.ejhg.5201773.

10. Klünder-Klünder M, Mejía-Benitez MA, FloresHuerta S, Burguete-García AI, García-Mena J, Cruz M. rs12255372 variant of TCF7L2 gene is protective for obesity in Mexican children. Arch Med Res. 2011;42(6):495-501. DOI: 10.1016/j.arcmed.2011.05.006. 
11. Palmer ND, Lehtinen AB, Langefeld CD, Campbell JK, Haffner SM, Norris JM, et al. Association of TCF7L2 gene polymorphisms with reduced acute insulin response in Hispanic Americans. J Clin Endocrinol Metab. 2008;93(1):304-9. DOI: 10.1210/jc.2007-1225.

12. Amoli MM, Amiri P, Tavakkoly-Bazzaz J, Charmchi E, Hafeziyeh J, Keramatipour M, et al. Replication of TCF7L2 rs7903146 association with type 2 diabetes in an Iranian population. GENET MOL BIOL. 2010;33(3):449-51. DOI: 10.1590/S141547572010005000056.

13. Cauchi S, El Achhab Y, Choquet H, Dina C, Krempler F, Weitgasser R, et al. TCF7L2 is reproducibly associated with type 2 diabetes in various ethnic groups: a global meta-analysis. J Mol Med. 2007;85(7):777-82. DOI: $10.1007 / \mathrm{s} 00109-007-0203-4$.

14. Barra GB, Dutra LAS, Watanabe SC, Costa PGG, Cruz PSMd, Azevedo MF, et al. Association of the rs7903146 single nucleotide polymorphism at the Transcription Factor 7-like 2 (TCF7L2) locus with type 2 diabetes in Brazilian subjects. Arq Bras Endocrinol Metab. 2012;56(8):479-84. DOI: 10.1590/S000427302012000800003.

15. Wegner L, Hussain MS, Pilgaard K, Hansen T, Pedersen O, Vaag A, et al. Impact of TCF7L2 rs7903146 on insulin secretion and action in young and elderly Danish twins. J Clin Endocrinol Metab. 2008;93(10):4013-9. DOI: $10.1210 /$ jc.2008-0855.

16. Luo Y, Wang H, Han X, Ren Q, Wang F, Zhang X, et al. Meta-analysis of the association between SNPs in TCF7L2 and type 2 diabetes in East Asian population. Diabetes Res Clin Pract. 2009;85(2):139-46. DOI: 10.1016/j.diabres.2009.04.024.

17. Ng MC, Tam CH, Lam VK, So W-Y, Ma RC, Chan JC. Replication and identification of novel variants at TCF7L2 associated with type 2 diabetes in Hong Kong Chinese. J Clin Endocrinol Metab. 2007;92(9):3733-7. DOI: $10.1210 /$ jc.2007-0849.
18. Tangjittipokin W, Chongjarean N, Plengvidhya N, Homsanit M, Yenchitsomanus P-t. Transcription factor 7-like 2 (TCF7L2) variations associated with earlier age-onset of type 2 diabetes in Thai patients. J Genet. 2012;91(2):251-5. DOI: 10.1007/s12041-012-0176-0.

19. Qiao H, Zhang X, Zhao X, Zhao Y, Xu L, Sun H, et al. Genetic variants of TCF7L2 are associated with type 2 diabetes in a northeastern Chinese population. Gene. 2012;495(2):115-9. DOI: 10.1016/j.gene.2011.12.055.

20. Chang Y-C, Chang T-J, Jiang Y-D, Kuo S-S, Lee $\mathrm{K}-\mathrm{C}$, Chiu KC, et al. Association study of the genetic polymorphisms of the transcription factor 7-like 2 (TCF7L2) gene and type 2 diabetes in the Chinese population. Diabetes. 2007;56(10):2631-7. DOI: 10.2337/ db07-0421.

21. Hayashi T, Iwamoto Y, Kaku K, Hirose H, Maeda S. Replication study for the association of TCF7L2 with susceptibility to type 2 diabetes in a Japanese population. Diabetologia. 2007;50(5):980-4. DOI: 10.1007/ s00125-007-0618-z.

22. Horikoshi M, Hara K, Ito C, Nagai R, Froguel P, Kadowaki T. A genetic variation of the transcription factor 7-like 2 gene is associated with risk of type 2 diabetes in the Japanese population. Diabetologia. 2007;50(4):747-51. DOI: 10.1007/s00125-006-0588-6.

23. Pang D, Smith A, Humphries S. Functional analysis of TCF7L2 genetic variants associated with type 2 diabetes. Nutr Metab Cardiovasc Dis. 2013;23(6):550-6. DOI: 10.1016/j.numecd.2011.12.012.

24. Karnes JH, Gong Y, Pacanowski MA, McDonough $\mathrm{CW}$, Arwood MJ, Langaee TY, et al. Impact of TCF7L2 single nucleotide polymorphisms on hydrochlorothiazide-induced diabetes. Pharmacogenet Genomics. 2013;23(12):697. DOI: 10.1097/ FPC.0000000000000012. 